Research Article

\title{
Experimental Study on the Deformation and Permeability Characteristics of Raw Coal under the Coupling Effect of Confining Pressure and Pore Pressure
}

\author{
Kangwu Feng $\mathbb{D},{ }^{1,2}$ Kequan Wang $\mathbb{D}^{2,3}$ and Yushun Yang $\mathbb{D}^{4}$ \\ ${ }^{1}$ School of Resources and Safety Engineering, Chongqing University, Chongqing 400044, China \\ ${ }^{2}$ Chongqing Institute of China Coal Research Institute, Chongqing 400037, China \\ ${ }^{3}$ State Key Laboratory of the Gas Disaster Decting, Preventing and Emergency Controlling, Chongqing 400037, China \\ ${ }^{4}$ Faculty of Architecture and Civil Engineering, Huaiyin Institute of Technology, Huaian 223001, China
}

Correspondence should be addressed to Kangwu Feng; fengkangwu.no.1@163.com

Received 2 April 2021; Accepted 30 June 2021; Published 9 July 2021

Academic Editor: Tomasz Trzepieciński

Copyright (C) 2021 Kangwu Feng et al. This is an open access article distributed under the Creative Commons Attribution License, which permits unrestricted use, distribution, and reproduction in any medium, provided the original work is properly cited.

The effects of confining pressure and pore pressure on the deformation and permeability characteristics of raw coal are studied experimentally. The deformation properties of raw coal by fracture and its permeability evolution laws under the coupling effect of confining pressure and pore pressure were further studied using a tri-axial servo-controlled seepage system for thermo-fluid-solid coupling of methane-bearing coal. The effects of confining pressure and gas pressure on the strength, elastic modulus, and permeability of raw coal were also analyzed. From the results, it was observed that rise in the confining pressure results in reduction of the initial permeability of raw coal and simultaneously increase its strength which results in higher axial deformation upon failure. Rise in gas pressure would increase the permeability and axial strain of raw coal on the whole and reduce its peak strength. Permeability first decreased and then increased during the loading of deviator stress, following a "V-shaped" change pattern. The results of sensitivity analysis indicated that confining pressure more significantly affected the peak strength and elastic modulus than gas pressure, while the gas pressure more significantly affected the permeability of the material than its confining pressure.

\section{Introduction}

Underground geotechnical engineering usually faces complex problems of multiphysics coupling, such as the coupling of ground stress field and flow field. Coal-rock mass is a typical pore-fissure dual medium, whose deformation and mechanical properties are greatly complicated by the migration of fluids in pore spaces. With the increasing depletion of resources in shallow strata, coal mining is inexorably proceeding towards deep strata. Deep strata are located in stress environments mainly characterized by high ground stress, high pore pressure, and complex geological structures, which add to the difficulties of coal mining, and hence, the growing risks of underground dynamic disasters (such as coal and gas outbursts and gas and dust explosions).
To lower the risks of gas disasters, a frequently adopted approach in coal mining is to reduce the gas pressure in coal seams by predraining drilling gas. In this context, the deformation fracture properties and permeability characteristics of coal-rock mass under the coupling effect of confining pressure and pore pressure have emerged as a research hotspot among researchers at home and abroad in recent years [1-9].

So far, many researchers have studied the deformation characteristics of coal-rock mass at different confining pressures and pore pressures. Gray et al. [10] explored the effects of such pressures on the permeability of sandstone and discovered that its permeability within the elastic range decreased with the increase in confining pressure, but increased with the increase in pore pressure. Zoback and 
Byerlee [11] further verified the relationships of the permeability of Berea sandstone with confining pressure and pore pressure and found that pore pressure exerted a more significant effect on permeability than confining pressure. Yin et al. [12] probed into the effects of gas pressure on the deformation and seepage laws of raw coal in a confining pressure unloading test at a given axial pressure and discovered that a higher gas pressure led to more obvious deformation of raw coal, lower peak strength, and faster growth of permeability after confining pressure unloading. Zhao et al. [13] inquired into the deformation and failure characteristics of sandstone under different combinations of confining pressure and pore pressure, found that gas pressure would reduce the strength and the elastic modulus of rocks, and accelerate their deformation. Zhang et al. [14] discovered that increased gas pressure would weaken specimen resistance to deformation and failure, intensify the effects of confining pressure on radial strain and volumetric strain, and reduce the sensitivity of axial strain to confining pressure, resulting in significant increases in the total energy and dissipative energy stored in raw coal upon failure.

The above research findings are very meaningful for fully understanding the effects of confining pressure and pore pressure on the deformation and seepage characteristics of the coal-rock mass. However, existing studies rarely attempt to quantify the effects of confining pressure and pore pressure on the mechanical properties and permeability of coal-rock mass. In view of this, this study experimentally studied the strength characteristics and seepage laws of raw coal at different confining pressures and gas pressures and quantified the effects of confining pressure and gas pressure on the strength, elastic modulus, and permeability of raw coal through sensitivity analysis.

\section{Specimens and Test Scheme}

2.1. Specimen Preparation. The raw coal used in this test was collected from the Baijiao Coal Mine of Sichuan Coal Industry Group Co., Ltd. Large lump coal was cut and polished in the laboratory to prepare standard raw coal specimens $\phi 50 \times 100 \mathrm{~mm}$ in size. The end-face roughness of specimens was uniformly controlled within $0.05 \mathrm{~mm}$, and their density was $1.506 \mathrm{~g} / \mathrm{cm}^{3}$. Figure 1 shows prepared raw coal specimens.

2.2. Test Equipment. The test was carried out using equipment for thermo-fluid-solid coupling of gas-bearing coal-rock mass, independently developed by Chongqing University [15], as shown in Figure 2. The equipment consists of loading control system, stress/strain collection and analysis system, internal sealed seepage system, acoustic emission monitoring system, etc. It applies to failure, seepage, and hydro-fracture tests on two specimens of dimensions $(\phi 50 \times 100 \mathrm{~mm})$ and $(\phi 100 \times 200 \mathrm{~mm})$ under multiple coupling conditions of mining-induced stress path, gas pressure, and temperature. It can provide a maximum axial pressure of $1,000 \mathrm{kN}$, a maximum radial pressure of $60 \mathrm{MPa}$, and a maximum gas pressure of $6 \mathrm{MPa}$.

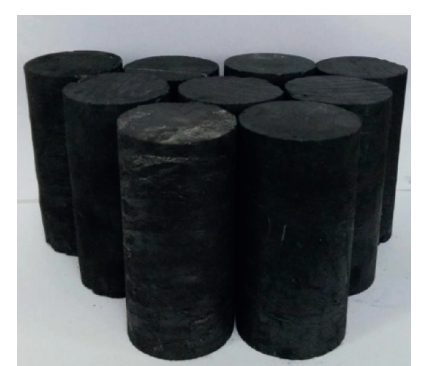

Figure 1: Standard raw coal specimens.

2.3. Test Scheme. In this study, raw coal specimens were loaded in the loading chamber, where the axial pressure $\sigma_{1}$ and the confining pressure $\sigma_{3}$ were raised at the rate of $0.2 \mathrm{kN} / \mathrm{s}$ until the hydrostatic pressure of $8 \mathrm{MPa}$. Compressed gas under $1 \mathrm{MPa}$ pressure was led through the inlet end, and the test conducted when specimens were saturated and outlet flow became stable. Following the test loading scheme shown in Figure 3 and Table 1, $\sigma_{3}$ and pore pressure were kept constant, and specimens were loaded by means of displacement-controlled loading at a rate of $0.00167 \mathrm{~mm} / \mathrm{s}$ until instability failure occurred. After that, the test was continued with new specimens. First, axial pressure and confining pressure were raised to the target values, and $\sigma_{3}$ was lowered at a rate of $0.02 \mathrm{MPa} / \mathrm{s}$ to $6 \mathrm{MPa}$ and $4 \mathrm{MPa}$, respectively. Gas pressure was reset from $1 \mathrm{MPa}$ to $2 \mathrm{MPa}$ and $3 \mathrm{MPa}$, and specimens were again loaded by means of displacement-controlled loading until failure occurred. Outlet flow was monitored throughout the loading process using a mass flowmeter.

The permeabilities of specimens loaded under deviator stress at different confining pressures and pore pressures were calculated according to Darcy's law [12, 15], as expressed by the following formula:

$$
k=\frac{2 q \mu L P_{2}}{A\left(P_{1}^{2}-P_{2}^{2}\right)},
$$

where $k$ is the permeability of the raw coal specimen, $\mathrm{m}^{2}, L$ is the length of the raw coal specimen, $\mathrm{m}, q$ is the gas flow under standard conditions, $\mathrm{m}^{3} / \mathrm{s}, \mu$ is the dynamic viscosity of the gas, $\mu \mathrm{Pa} \cdot \mathrm{s}, A$ is the cross-sectional area of the raw coal specimen, $\mathrm{m}^{2}, P_{2}$ is the atmospheric pressure, $\mathrm{MPa}$, and $P_{1}$ is the gas pressure at the inlet end, MPa.

\section{Test Results and Analysis}

\subsection{Effects of Confining Pressure on the Deformation Fracture} and Permeability of Raw Coal. Figure 4 shows the curves of deviator stress $\left(\sigma_{1}-\sigma_{3}\right)$ and permeability $k$ changing with axial strain $\varepsilon_{1}$ for raw coal specimens at different confining pressures (gas pressure $=1,2$, and $3 \mathrm{MPa}$ ). Clearly, with the increase of confining pressure, the initial permeability of raw coal declined. Permeability first decreased and then increased during the loading phase of deviator stress. The strength and axial strain $\varepsilon_{1}$ upon failure both increased with the increase of confining pressure. For instance, at the given gas pressure of $1 \mathrm{MPa}$, the raw coal specimen with a 


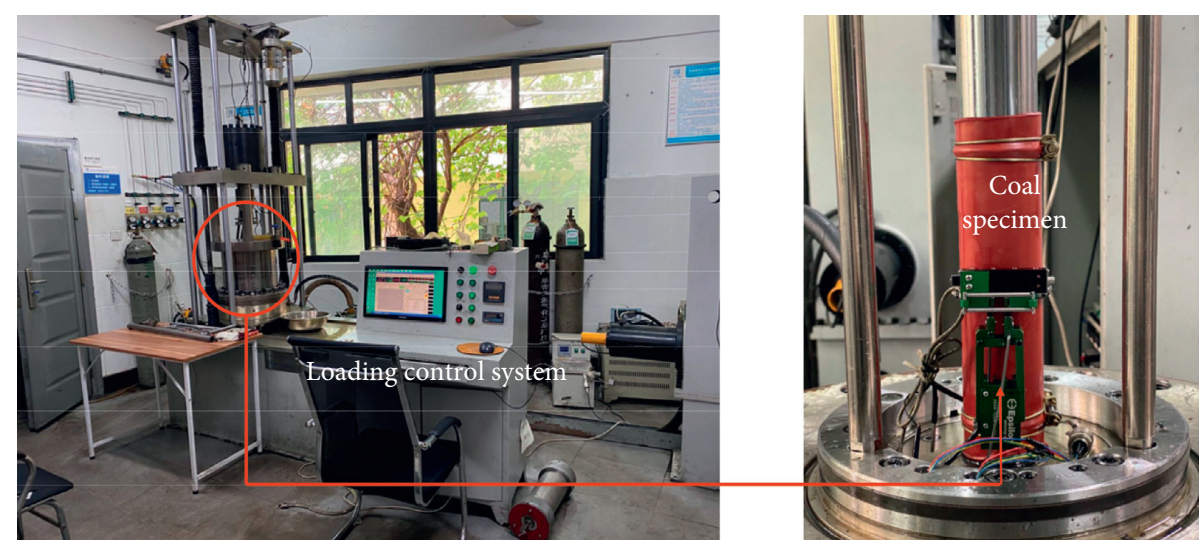

FIGURE 2: Equipment for thermo-fluid-solid coupling of gas-bearing coal-rock mass.

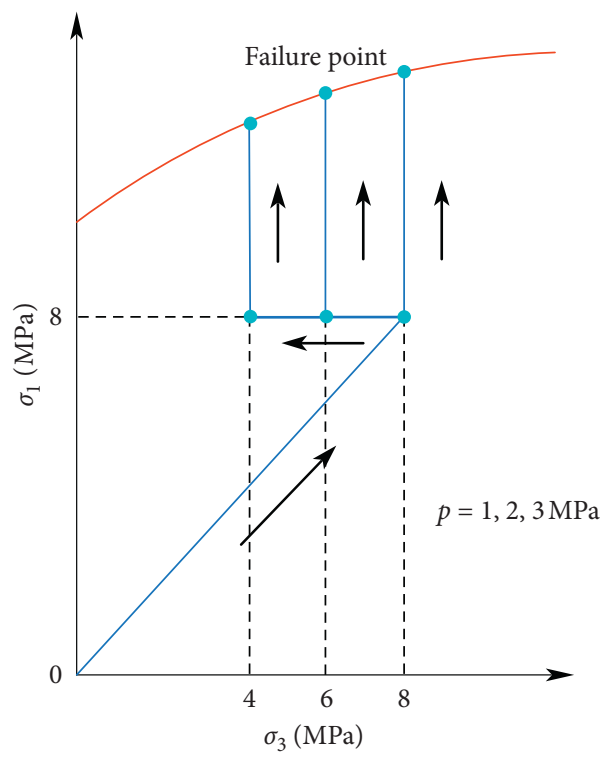

FIgUre 3: Test loading path.

TABle 1: Test loading scheme.

\begin{tabular}{|c|c|c|c|}
\hline Axial pressure $(\mathrm{MPa})$ & Confining pressure (MPa) & Pore pressure $(\mathrm{MPa})$ & Axial pressure loading rate $(\mathrm{mm} / \mathrm{s})$ \\
\hline \multirow{3}{*}{8} & & 1 & \\
\hline & 4 & 2 & 0.00167 \\
\hline & & 3 & \\
\hline \multirow{3}{*}{8} & & 1 & \\
\hline & 6 & 2 & 0.00167 \\
\hline & & 3 & \\
\hline \multirow{3}{*}{8} & & 1 & \\
\hline & 8 & 2 & 0.00167 \\
\hline & & 3 & \\
\hline
\end{tabular}

confining pressure of $4 \mathrm{MPa}$ had an initial permeability of $6.75 \mathrm{mD}$, a peak strength of $44.85 \mathrm{MPa}$, and an axial strain $\varepsilon_{1}$ upon failure of $1.49 \%$. The raw coal specimen with a confining pressure of $6 \mathrm{MPa}$ had an initial permeability of $6.02 \mathrm{mD}$, a peak strength of $54.75 \mathrm{MPa}$, and an axial strain $\varepsilon_{1}$ upon failure of $1.80 \%$. The raw coal specimen with a confining pressure of $8 \mathrm{MPa}$ had an initial permeability of
$4.68 \mathrm{mD}$, a peak strength of $67.02 \mathrm{MPa}$, and an axial strain $\varepsilon_{1}$ upon failure of $1.83 \%$. This change in permeability values can be attributed to the fact that increased initial confining pressure compressed the pores and fissures in the specimens, resulting in the decline of the initial permeability of raw coal. During the loading phase of deviator stress, pore and fissure areas were further reduced, giving rise to a continuous 


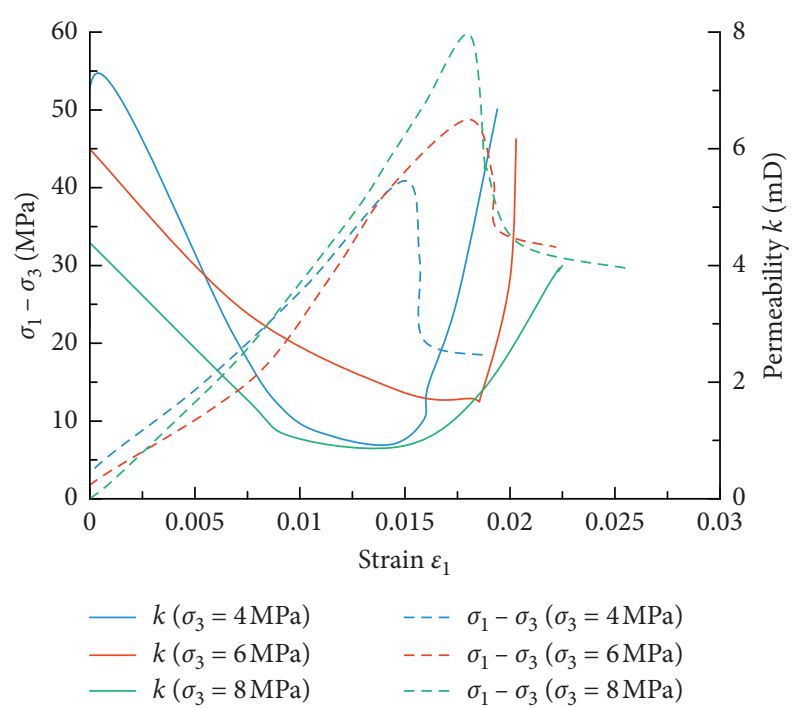

(a)

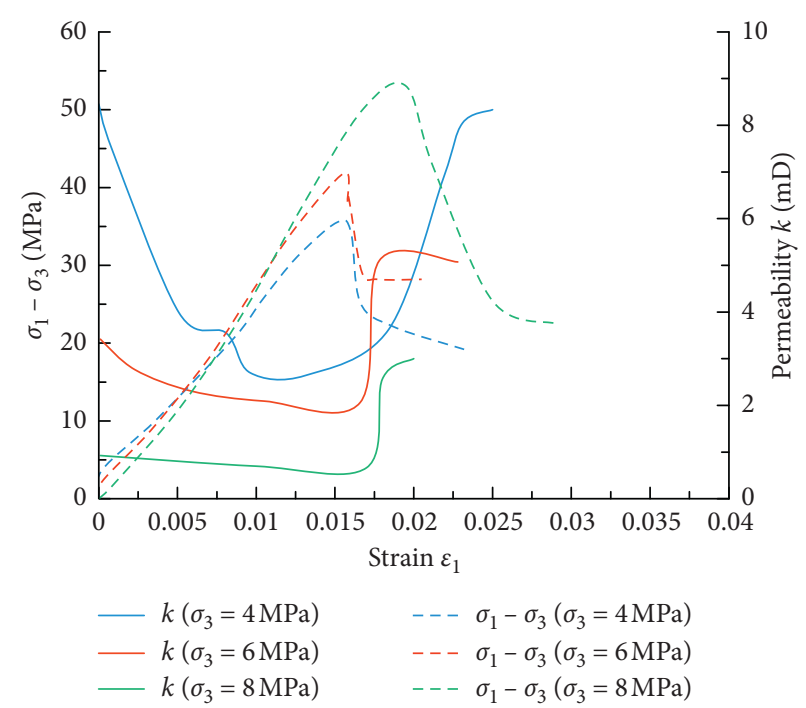

(b)

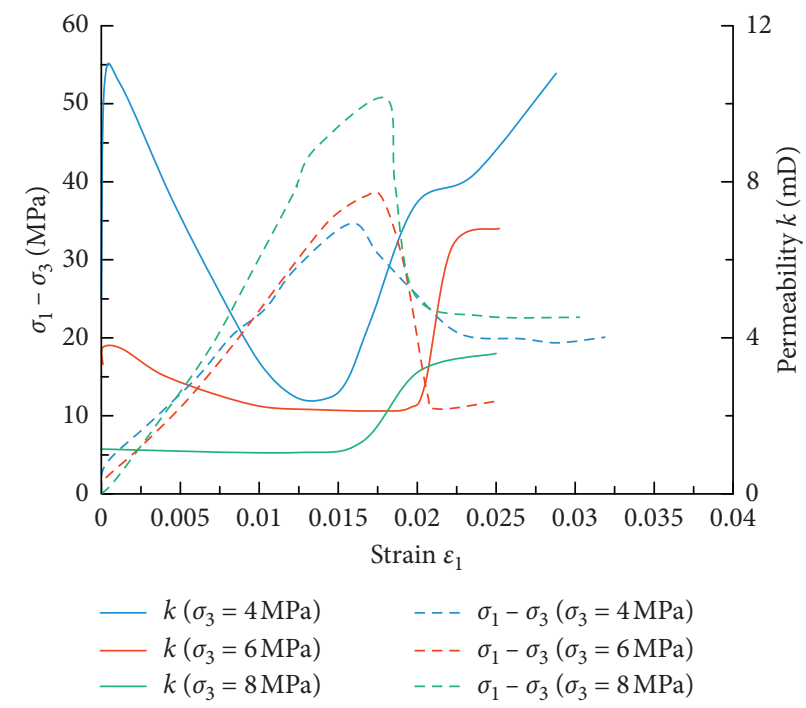

(c)

FIGURE 4: Stress-strain-permeability changes of raw coal at different confining pressures. (a) Stress-strain-permeability changes of raw coal at different confining pressures (gas pressure $=1 \mathrm{MPa}$ ). (b) Stress-strain-permeability changes of raw coal at different confining pressures (gas pressure $=2 \mathrm{MPa}$ ). (c) Stress-strain-permeability changes of raw coal at different confining pressures $($ gas pressure $=3 \mathrm{MPa})$.

decline of permeability. However, with the continuous loading of deviator stress, cracks initiated, propagated, and coalesced, resulting in enhanced permeability. Increased confining pressure can limit the propagation of cracks. This explains why increasing confining pressure helps to increase the strength of raw coal specimens and intensifies the axial deformation of raw coal under the same loading rate.

3.2. Effects of Gas Pressure on the Deformation Fracture and Permeability of Raw Coal. Figure 5 shows the curves of deviator stress $\left(\sigma_{1}-\sigma_{3}\right)$ and permeability $k$ changing with axial strain $\varepsilon_{1}$ for raw coal specimens at different gas pressures when confining pressure was $8 \mathrm{MPa}$ and the specimens were unloaded from $8 \mathrm{MPa}$ to $6 \mathrm{MPa}$ and $4 \mathrm{MPa}$, respectively. As can be seen from Figure 5, with the decline of confining pressure in the unloading process of initial confining pressure, the initial permeability of raw coal increased, and $\varepsilon_{1}$ rose up as well. Lowering the confining pressure led to increased pore spaces, expanded seepage channels, and increased permeability in raw coal specimens, together with the occurrence of axial compression and the increase in axial deformation [16].

During the loading of deviator stress, permeability also first decreased and then increased, presenting a "V-shaped" change pattern. On the whole, permeability would increase with the increase of gas pressure, while the strength upon failure would decline with the increase of gas pressure, accompanied by the increase in $\varepsilon_{1}$. For instance, at the confining pressure of $4 \mathrm{MPa}$, when raw coal was subjected to gas 


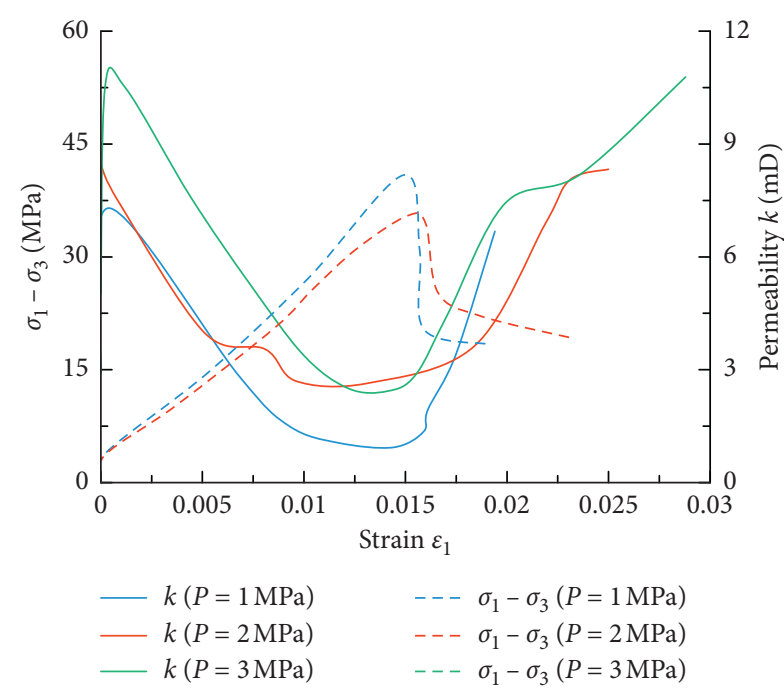

(a)

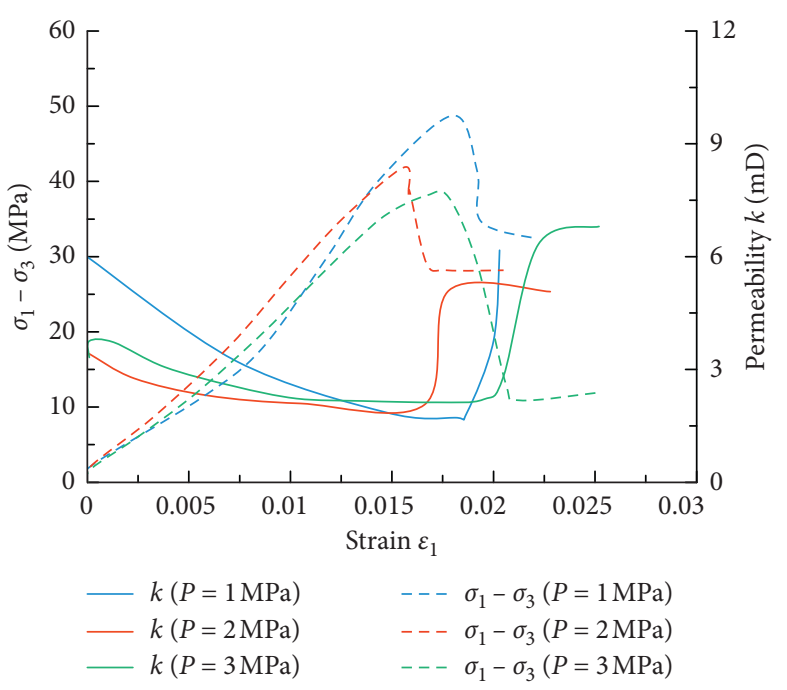

(b)

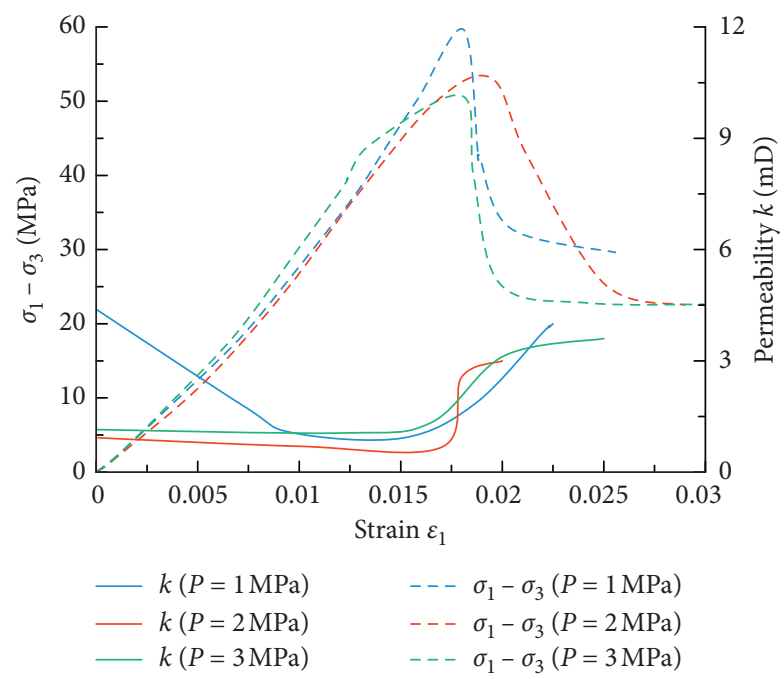

(c)

FIGURE 5: Stress-strain-permeability changes of raw coal at different gas pressures. (a) Stress-strain-permeability changes of raw coal at different gas pressures (confining pressure unloaded to $4 \mathrm{MPa}$ ). (b) Stress-strain-permeability changes of raw coal at different gas pressures (confining pressure unloaded to $6 \mathrm{MPa}$ ). (c) Stress-strain-permeability changes of raw coal at different gas pressures (confining pressure unloaded to $8 \mathrm{MPa})$.

pressures of $1 \mathrm{MPa}, 2 \mathrm{MPa}$, and $3 \mathrm{MPa}$, its peak permeabilities were $6.75 \mathrm{mD}, 8.14 \mathrm{mD}$, and $9.37 \mathrm{mD}$, respectively; its peak strengths were $44.85 \mathrm{MPa}, 39.49 \mathrm{MPa}$, and $38.65 \mathrm{MPa}$, respectively; its $\varepsilon_{1}$ values were $1.49 \%, 1.51 \%$, and $1.58 \%$, respectively. This can be attributed to the fact that increased gas pressure reduced the effective stress in raw coal specimens, thus increasing pore and fissure areas and causing the expansion and enhanced permeability of raw coal. In addition, it also weakened the bearing capacity of raw coal specimens and increased $\varepsilon_{1}$ upon reaching peak strength.

On the contrary, increased pore pressure would produce a bigger flow along the gas flow direction and a greater pressure difference in pore spaces, resulting in a larger thrust. Driven by the thrust, the fine particles blocking fluid seepage paths in the matrix would be separated from the matrix and burst out of the fissures under a greater pressure difference. As a result, fluid seepage paths would be smoothened, thus enhancing the permeability of raw coal [17]. The differences of bedding and cleat distribution and fracture compressibility also change the permeability trend.

\section{Discussion}

4.1. Effects of Confining Pressure and Gas Pressure on Strength and Elastic Modulus. Figure 6 shows the variations in strength of raw coal upon failure at different confining pressures and gas pressures. It can be seen that the strength upon failure increased exponentially with the increase of confining pressure and decreased linearly with the increase of pore pressure. Figure 7 shows the elastic modulus $E$ change curves of raw coal at different confining pressures and gas pressures. Elastic modulus presented a linear 


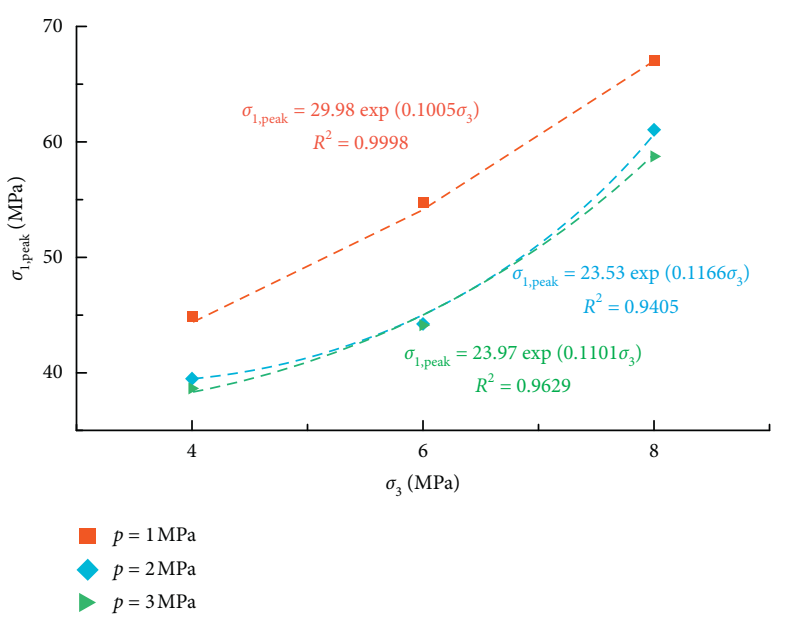

(a)

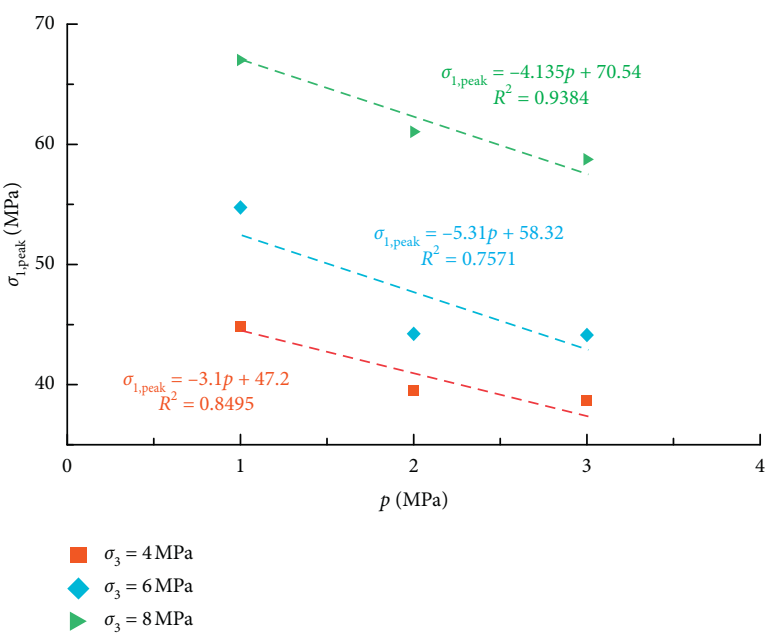

(b)

Figure 6: Peak strength change curves of raw coal at different confining pressures and gas pressures. (a) Curves of strength changing with confining pressure. (b) Curves of strength changing with gas pressure.

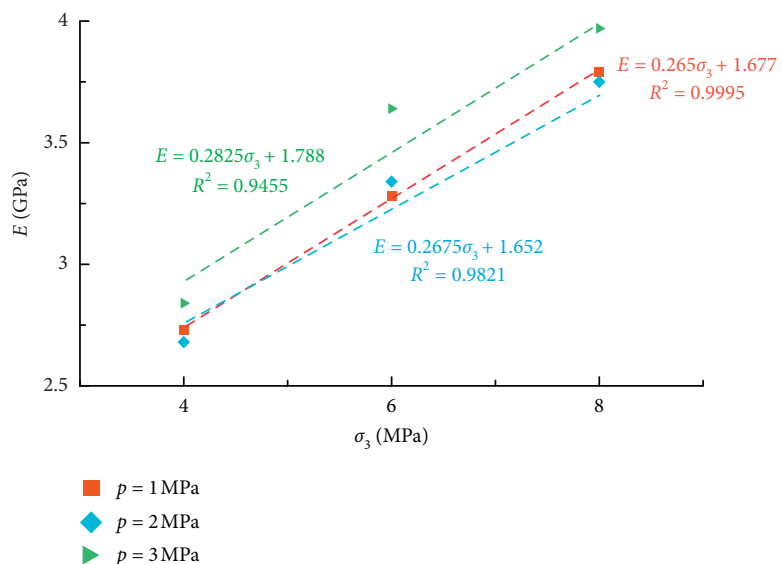

(a)

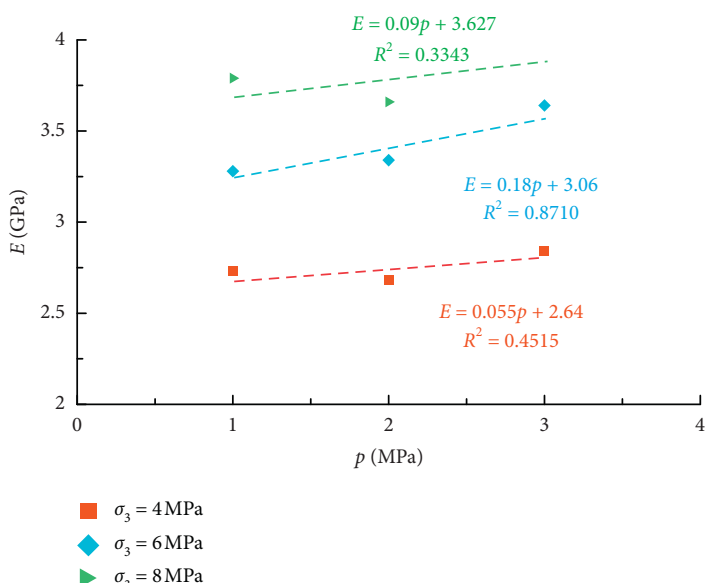

(b)

FIGURE 7: Elastic modulus $E$ change curves of raw coal at different confining pressures and gas pressures. (a) Curves of elastic modulus $E$ changing with confining pressure. (b) Curves of elastic modulus $E$ changing with gas pressure.

increase with the increase of confining pressure, also suggesting that increased confining pressure significantly enhanced the deformation resistance of raw coal specimens. However, with the increase of gas pressure, the elastic modulus shows different variation rules, but the overall trend also shows a linear upward trend.

To quantify the effects of confining pressure and gas pressure on strength and elastic modulus, the variation of strength and elastic modulus with respect to these parameters were characterized through sensitivity analysis. The sensitivity analysis is a method of identifying the potential connections between the physico-mechanical parameters of rocks. It is often used to quantify the effects of rock density, porosity, moisture, and other indices on mechanical parameters (such as compressive strength, elastic modulus, and Poisson's ratio) [18]. An array can be constructed using all the data pairs in experimental data (Figures 6 and 7):

$$
X=\left\{x_{1}, x_{2}, x_{3}, \ldots, x_{i}, \ldots x_{n}\right\}
$$

where $x_{i}$ is the parametric variable with a length of $\mathrm{m}$, which denotes sensitivity parameters $\left(\sigma_{3}\right.$ and $\left.p\right)$ and effect parameters $\left(\sigma_{1, \text { peak }}\right.$ and $\left.E\right)$ :

$$
x_{i}=\left\{x_{i 1}, x_{i 2}, x_{i 3}, \ldots, x_{i m}\right\} \text {, }
$$

where $x_{i m}$ is the specific value of each parameter (Figures 6 and 7). The relationship between sensitivity parameter $x_{i}$ and effect parameter $x_{j}$ can be described using coefficient $r_{i j}[19]$ :

$$
r_{i j}=\frac{\sum_{k=1}^{m} x_{i k} x_{j k}}{\sqrt{\sum_{k=1}^{m} x_{i k}^{2} \sum_{k=1}^{m} x_{j k}^{2}}} .
$$

When the value of $r_{i j}$ is greater, the effects of the corresponding parameter on $\sigma_{1 \text {,peak }}$ and $E$ are more 


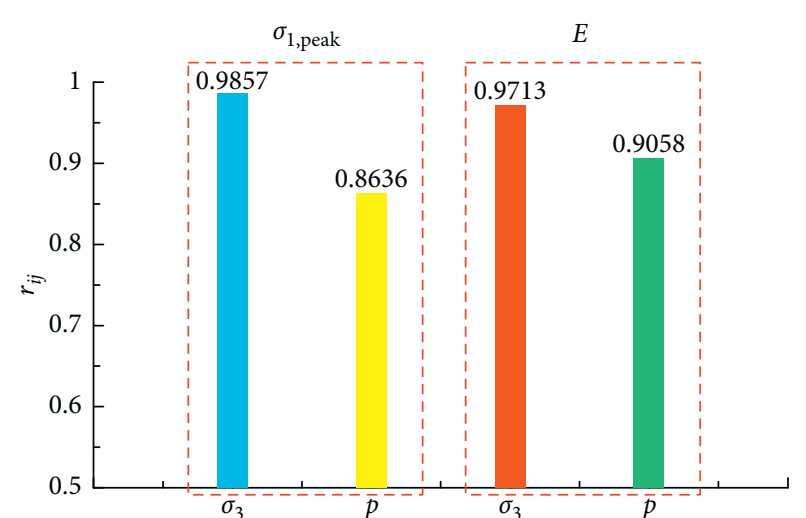

FIGURE 8: Sensitivity analysis results of strength and elastic modulus.

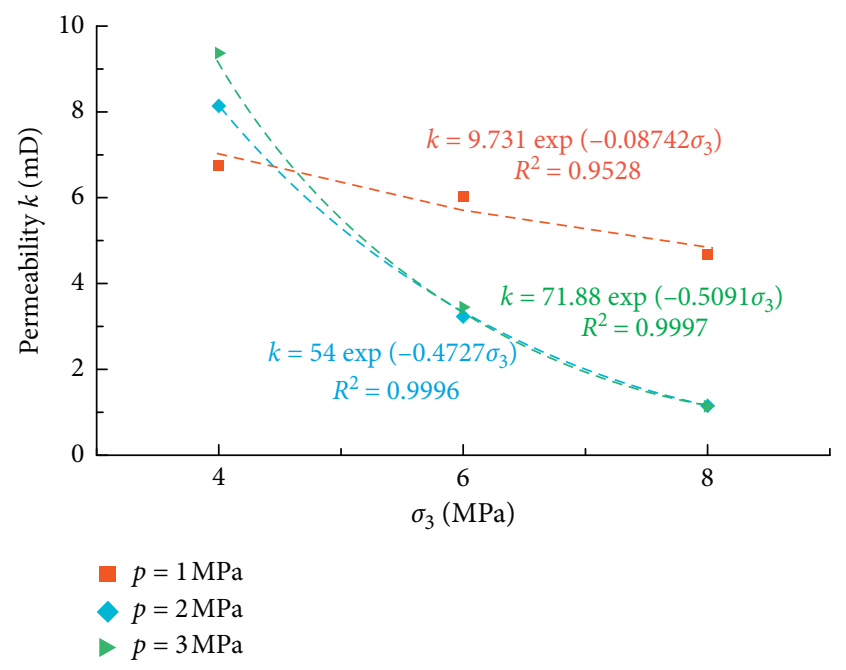

Figure 9: Permeability change curves of raw coal at different confining pressures.

significant as well. Figure 8 is a sensitivity analysis histogram characterizing the sensitivity of the peak strength and the elastic modulus to changes in the confining pressure and gas pressure. It can be known that the calculation coefficient $r_{i j}$ of confining pressure was greater than that of gas pressure, suggesting that confining pressure more significantly affected peak strength and elastic modulus than gas pressure.

4.2. Effects of Confining Pressure and Gas Pressure on Permeability. Figure 9 shows the permeability change trends of raw coal upon failure at different confining pressures. It can be seen that permeability declined exponentially with the increase of confining pressure. Formula (4) is also employed in this part to calculate the sensitivity of confining pressure and gas pressure to permeability. Figure 10 shows the sensitivity analysis histogram characterizing the sensitivity of permeability of the specimen to the changes in confining pressure and gas pressure. It can be seen that the calculation coefficient $r_{i j}$ of gas pressure was greater than that of confining pressure,

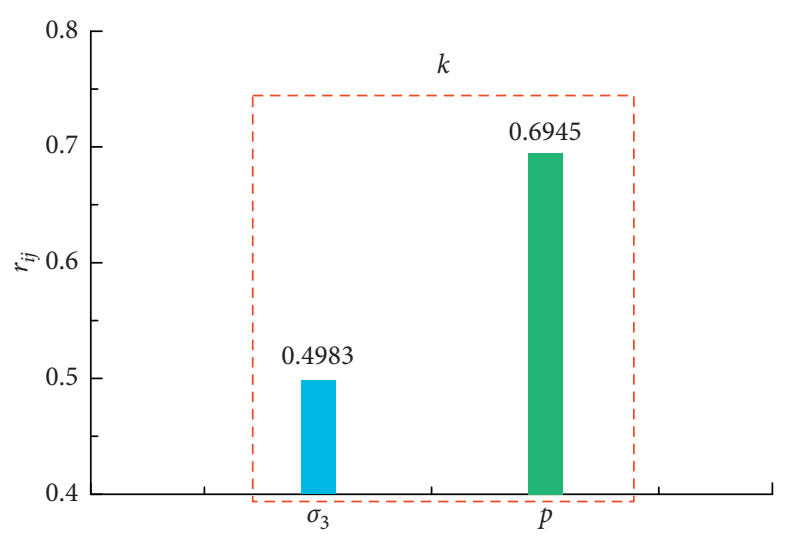

FIgURE 10: Sensitivity analysis results of permeability.

suggesting that gas pressure more significantly affected permeability than confining pressure.

\section{Conclusions}

This study explored the evolution laws of the mechanical properties and permeability of raw coal under the coupling effect of confining pressure and pore pressure. The main conclusions are as follows:

(1) With the increase of confining pressure, the initial permeability of raw coal declined. Permeability first decreased and then increased during the loading phase involving increase in the deviator stress. With the increase inconfining pressure, the strength upon failure increased exponentially, elastic modulus presented a linear increase, and axial strain to failure increased as well.

(2) Similarly, at different gas pressures, permeability first decreased and then increased during the loading phase involving rise in the deviator stress, presenting a "V-shaped" change pattern. On the whole, permeability would increase with the increase of gas pressure, while the strength upon failure would decline linearly with the increase in gas pressure, accompanied by the increase in axial strain.

(3) To quantify the effects of confining pressure and gas pressure on the peak strength, the elastic modulus, and the permeability of raw coal, the change laws of mechanical parameters were determined through a quantitative sensitivity analysis. According to the results, it can be concluded that the effect of confining pressure on the peak strength and elastic modulus is more significant than that of gas pressure, while the effect of gas pressure on the permeability of raw coal is more significant than that of the confining pressure.

\section{Data Availability}

The data used to support the findings of this study are included within the article. 


\section{Conflicts of Interest}

The authors declare no conflicts of interest.

\section{References}

[1] H. Zhou, H. Xie, and J. Zuo, "Developments in researches on mechanical behaviors of rocks under the condition of high ground pressure in the depths," Advances in Mechanics, vol. 35, no. 1, pp. 91-99, 2005.

[2] K. Xia, S. Wang, Y. Xu, R. Chen, and B. Wu, "Advances in experimental studies for deep rock dynamics," Chinese Journal of Rock Mechanics and Engineering, vol. 40, no. 3, pp. 448-475, 2021.

[3] G. Yin, X. Li, J. Lu, and M. Li, "Disaster-causing mechanism of compound dynamic disaster in deep mining under static and dynamic load conditions," Journal of China Coal Society, vol. 42, no. 9, pp. 2316-2326, 2017.

[4] D. Zhang, B. Zheng, G. Yin, X. Zhang, and Y. Yang, "Mechanics and permeability characteristics of steep seam roof sandstone under disturbance stress," Journal of China Coal Society, vol. 42, no. S1, pp. 128-137, 2017.

[5] H. Zhao, D. Zhang, C. Liu, B. Deng, Bianguang, and W. Li, "Mechanical characteristics and permeability evolution rule of coal under loading-unloading conditions," Chinese Journal of Engineering, vol. 38, no. 12, pp. 1674-1680, 2016.

[6] H. Wang, P. Fan, M. Wang, W. Li, and Y. Qian, "Influence of strain rate on progressive failure process and characteristic stresses of red sandstone," Rock and Soil Mechanics, vol. 32, no. 5, pp. 1340-1346, 2011.

[7] M. Li, G. Yin, J. Xu, W. Li, and Z. Song, "A novel true triaxial apparatus to study the geomechanical and fluid flow aspects of energy exploitations in geological formations," Rock Mechanics and Rock Engineering, vol. 49, no. 12, pp. 4647-4659, 2016.

[8] H. Xie, H. Zhou, J. Liu et al., "Mining-induced mechanical behavior in coal seams under different mining layouts," Journal of China Coal Society, vol. 36, no. 7, pp. 1067-1074, 2011.

[9] Y. Lü and H. Qin, "Investigation into mechanical responses and energy dissipation properties of coal containing methane to confinement unloading," Journal of China Coal Society, vol. 37, no. 9, pp. 1505-1510, 2012.

[10] D. H. Gray and I. Fatt, "The effect of stress on permeability of sandstone cores," Society of Petroleum Engineers Journal, vol. 3, no. 2, pp. 95-100, 1963.

[11] M. D. Zoback and J. D. Byerlee, "Permeability and effective stress: geologic notes," AAPG Bulletin, vol. 59, no. 1, pp. 154-158, 1975.

[12] G. Yin, M. Li, W. Li, C. Jiang, Caojie, and Q. Zhang, "Influence of gas pressure on mechanical and seepage characteristics of coal under unloading condition," Journal of China Coal Society, vol. 37, no. 9, pp. 1499-1504, 2012.

[13] H. Zhao, D. Zhang, W. Li, G. Bian, C. Liu, and C. Zhang, "Experimental study on influence of gas pressure on mechanical properties of sandstone," Chinese Journal of Rock Mechanics and Engineering, vol. 36, no. S1, pp. 3239-3246, 2017.

[14] D. Zhang, X. Zhang, Z. Rao, G. Qin, Y. Yang, and Y. Xue, "Impact of gas pressure on the mechanical properties and energy trend of coal under unloading condition," Journal of Safety and Environment, vol. 19, no. 1, pp. 203-209, 2019.

[15] G. Yin, W. Li, J. Xu et al., "Development and application of fracturing and seepage experimental system for multi-physical field and multiphase coupling of porous media," Chinese Journal of Rock Mechanics and Engineering, vol. 35, no. S1, pp. 2853-2861, 2016.

[16] C. Liu, D. Zhang, D. Shang, H. Zhao, Z. Song, and H. Yu, "Influence of confining pressure unloading at post-peak on deformation and permeability characteristics of raw coal," Rock and Soil Mechanics, vol. 39, no. 6, pp. 2017-2024+2034, 2018.

[17] B. Yu, C. Liu, D. Zhang et al., "Experimental study on the anisotropy of the effective stress coefficient of sandstone under true triaxial stress," Journal of Natural Gas Science and Engineering, vol. 84, Article ID 103651, 2020.

[18] M. Khandelwal, R. S. Faradonbeh, M. Monjezi, D. J. Armaghani, M. Z. B. A. Majid, and S. Yagiz, "Function development for appraising brittleness of intact rocks using genetic programming and non-linear multiple regression models," Engineering with Computers, vol. 33, pp. 13-21, 2017.

[19] I. Enayatollahi, A. A. Bazzazi, and A. Asadi, "Comparison between neural networks and multiple regression analysis to predict rock fragmentation in open-pit mines," Rock $\mathrm{Me}$ chanics and Rock Engineering, vol. 47, no. 2, pp. 799-807, 2014. 